Stefan Duschek Rainer Schandry

\title{
Reduced brain perfusion and cognitive performance due to constitutional hypotension
}

Abstract This review article includes a systematic evaluation of the empirical data concerning deficits in mental ability, brain perfusion, and cerebral functioning due to chronically low blood pressure. A number of studies have provided strong evidence for reduced cognitive performance in hypotension, particularly in the domains of attention and memory. EEG studies have demonstrated that the hypotension-related poorer mental ability is also reflected in diminished cortical activity. Contrary to convention, more recent research has suggested a deficient regulation of cerebral blood flow in persons with low blood pressure. In addition to reduced tonic brain perfusion, studies demonstrated insufficient adjustment of blood flow to cognitive requirements. Altogether, these findings suggest that more attention should be allocated to chronic hypotension in both research and clinical practice.

Key words blood pressure . hypotension - cerebral blood flow $\cdot$ cognitive $\cdot$ autonomic nervous system

Fax: +49-89/2180-5233

E-Mail: duschek@psy.uni-muenchen.de

\section{Introduction}

Chronically low blood pressure is accompanied by a variety of complaints including fatigue, reduced drive, faintness, dizziness, headaches, palpitations, and increased pain sensitivity [1-4]. In addition, hypotensive individuals report cognitive impairment, above all deficits in attention and memory. Nevertheless, it is generally the case that in research, as well as in clinical practice, relatively little importance is ascribed to hypotension. One reason for this is that, despite mental symptoms, cerebral dysfunction generally is not taken into account [1]. This is a consequence of the current doctrine that low systemic blood pressure is compensated by autoregulatory processes which prevent reduced blood perfusion of the brain $[5,6]$.
Some recent findings challenge this doctrine: reduced cognitive performance in hypotension has been demonstrated by neuropsychological testing, and EEG studies have revealed diminished cortical activity. Moreover, the assumption of unimpaired brain perfusion in hypotension no longer holds. In the present review the necessity of a reappraisal concerning hypotension is discussed in light of the relationship between blood pressure and cerebral functioning.

\section{Constitutional hypotension}

Hypotension has been defined by the World Health Organization (WHO) [4] as a low blood pressure with a systolic reading below $110 \mathrm{mmHg}$ in males and below $100 \mathrm{mmHg}$ in females, regardless of diastolic 
blood pressure. The concept of constitutional hypotension refers to a chronic condition of inappropriately reduced blood pressure independent of the presence of further pathological factors. Both secondary hypotension (e.g. due to blood loss or medication) and orthostatic hypotension (caused by circulatory problems when assuming an upright position) are distinguished from the constitutional form $[1,6]$.

Constitutional hypotension is relatively widespread in the general population. In a representative German sample of more than 7,000 subjects approximately $3 \%$ fulfilled the criteria of the WHO [c.f. 1]. In contrast to elevated blood pressure, which constitutes a significant risk factor for cardiovascular disease, hypotension is commonly not regarded as a severe condition. Nevertheless, its impact on personal well-being and quality of life has been shown in several epidemiological studies. For instance, Wessely et al. [7], as well as Pilgrim et al. [3] demonstrated impaired physical and mental health in the case of low blood pressure. Reduced health-related quality of life [8] and a heightened degree of depressiveness [9] were also reported by hypotensive individuals.

Chronic hypotension has been identified as a major risk factor in pregnancy [10]. Moreover, several studies focusing on the elderly population have reported associations between low blood pressure and the prevalence and incidence of Alzheimer's and vascular dementia [c.f. 11-14]. Whilst a few longitudinal studies examining this relationship have been published $[15,16]$, the causal role of low blood pressure in degenerative brain disorders has thus far not been proven [e.g. 13]. ${ }^{1}$

Concerning the etiology of hypotension, reduced liquid intake and low body weight may be considered [c.f. 1, 17]. A dysregulation of the autonomous nervous system may additionally be of significance. Various findings on reduced electrodermal activity [18] and increased heart rate variability [19] reflect diminished sympathetic tone and habitually heightened parasympathetic activity in persons with low blood pressure values. This is corroborated by findings on the effects of sympathomimetic drugs [20,21]. In mixed samples of persons with constitutional and orthostatic hypotension, $\alpha$ and $\beta$ adrenergic substances were shown to lead to blood pressure elevation accompanied by a reduction of subjective symptoms. A malfunction of the arterial baroreceptor system was postulated as a further etiological factor [22]. Responding to mechanical stretch of the vessel

\footnotetext{
${ }^{1}$ The cited findings $[3,7-9,11-16]$ were revealed in large epidemiological studies. All included samples across the total blood pressure spectra and did not explicitly define hypotension according to the WHO criteria [4].
}

walls, the baroreceptors form part of a negative feedback loop ("baroreflex") compensating phasic blood pressure fluctuations [23]. Increased sensitivity of the baroreceptor system may result in stabilizing blood pressure at a lower level. In addition to findings in animals [24], this hypothesis is supported by a still unpublished study of our own group which yielded increased baroreflex sensitivity in the case of low blood pressure.

\section{Cognitive deficits in constitutional hypotension}

Table 1 presents the most relevant studies devoted to cognitive functioning in hypotension. In addition to the main results, the table includes information concerning the respective samples and assessment instruments.

A pioneering study investigating the relationship between blood pressure and cognitive abilities was conducted by Richter-Heinrich et al. [18]. They showed reduced performance of individuals with both lowered and elevated blood pressure on a test of concentration. A more comprehensive assessment was carried out by Stegagno et al. [26], in which poorer performances of hypotensive subjects on a verbal memory test and on an arithmetic task, as well as prolonged reaction times to acoustic stimuli were observed. Costa et al. [29] found reduced scores on two standard German paper-pencil tests assessing selective attention and cognitive speed. Moreover, as in the Stegagno et al. [26] study, impaired verbal memory performance was documented.

Weisz et al. [22] reported that female hypotensive subjects performed significantly worse than controls on a computer-based test measuring attentional flexibility [36]. Subjects with only a moderately decreased blood pressure were assessed by Duschek et al. [37]. In this sample, reduced attentional performance and prolonged reaction times were again found as compared to normotensive controls.

Duschek et al. [38] investigated the relationship between low blood pressure and attentional abilities through the application of a multidimensional diagnostic approach. They presented their subjects with a battery of six computer-based tasks [39] focusing on tonic and phasic alertness, selective, divided and sustained attention, as well as working memory. Additionally, in order to control for possible confounders, a test battery examining fine motor abilities [40] and a mood questionnaire [41] were presented. Reduced performance of hypotensives was evident in each of the six cognitive tests. The significant differences between hypotensive and control subjects persisted even when the effects of motor performance and mood were controlled. 


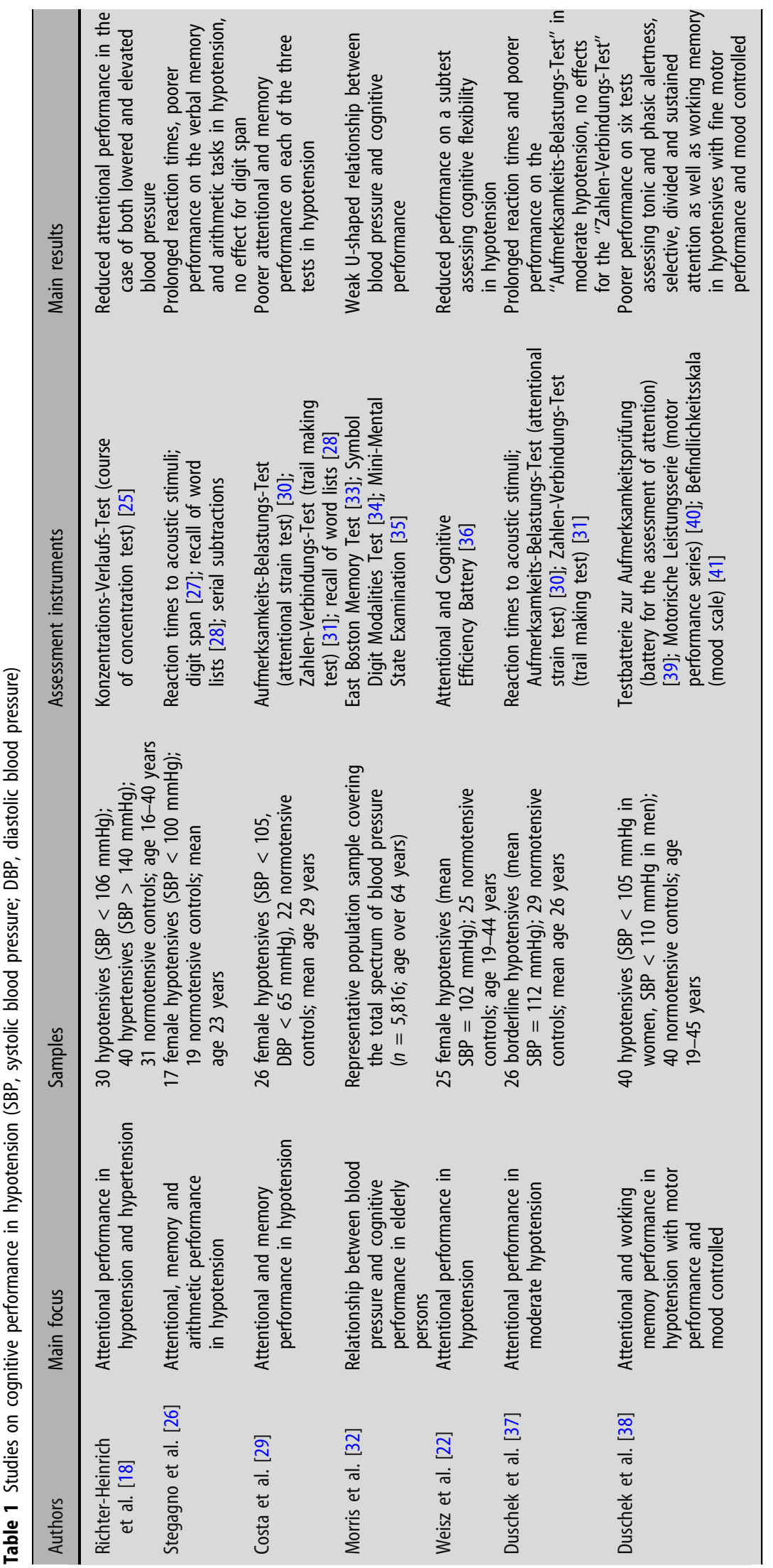




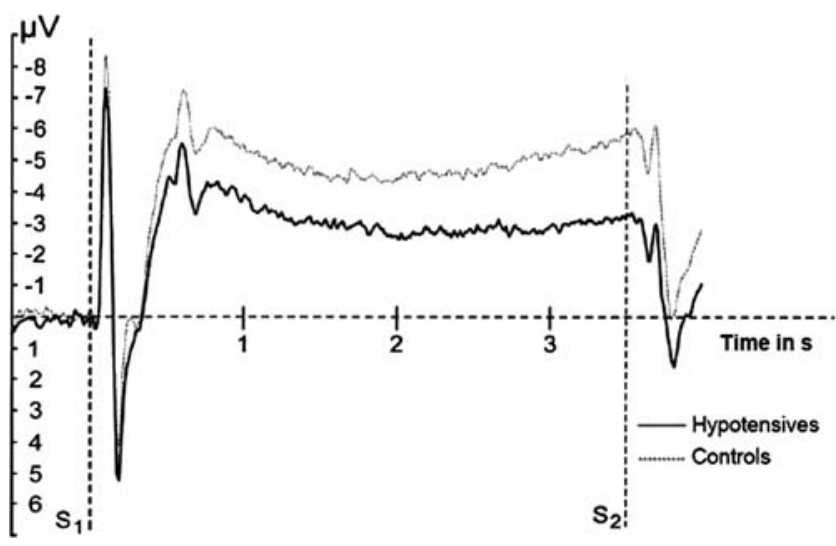

Fig. 1 The CNV occurs during the period between a warning signal (S1) and a second stimulus (S2) demanding a motor, verbal or cognitive response. As can be seen in the figure, its amplitude was found to be reduced in hypotensive subjects $(N=40)$ as compared to normotensive controls $(N=40)$; modified from [47]

Altogether, the existing data provide strong evidence for cognitive deficits related to constitutional hypotension, especially in the domains of attention and memory. The reduced performance seems to be a direct consequence of low blood pressure rather than an effect of impaired well-being related to this state. Up to now there have been no empirical data concerning specific effects of hypotension-related deficits on everyday life. Nonetheless, these findings raise concern regarding the impact of the deficits on attention-demanding activities (e.g. professional or academic), including public health-related functions (e.g. traffic safety) [42].

It would appear that both extremes of the blood pressure spectrum are accompanied by a decrease in cognitive ability. A number of studies concerned with elevated blood pressure showed reduced performance on various cognitive tests $[43,44]$. This is in line with epidemiological studies reporting an inverted Ushaped relationship between blood pressure and cognitive performance in elderly persons [c.f. 11, 13, 32, 45, 46]. Therefore, it may further be hypothesized that there is a relatively small range of normal blood pressure in which the brain exerts its optimal function.

\section{Neuroelectrophysiological correlates of hypotension-related cognitive deficits}

Cognitive deficits in low blood pressure states are also reflected in decreased cortical activity. In accordance with earlier results [22, 29], Duschek et al. [47] found the amplitude of the contingent negative variation (CNV) to be reduced in a hypotensive sample defined according to the WHO criteria [4] (c.f. Fig. 1).

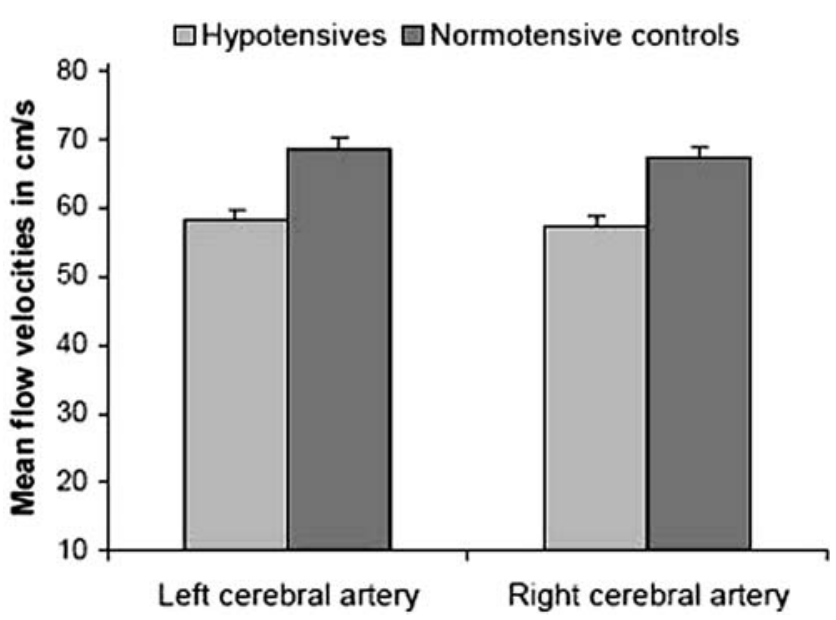

Fig. 2 Mean flow velocities in the left and right middle cerebral arteries under resting conditions in hypotensive $(N=40)$ and control subjects $(N=40)$; bars represent standard errors [65]

The CNV is an evoked potential which is generally viewed as a neuroelectrophysiological correlative of attentional processing [48]. This is supported by pharmacological studies showing that the effects of various stimulant and sedative drugs on attention involve an increase or decrease, respectively, of the CNV amplitude [49, 50]. Moreover, attentional deficits due to brain lesions and psychiatric diseases are associated with a reduced $\mathrm{CNV}[51,52]$. In the $\mathrm{Du}$ schek et al. [47] study, the amplitude of the CNV proved to be negatively correlated with reaction time, which in turn was prolonged in the hypotensive group. This highlights that the CNV constitutes a brain electrical correlate of an aspect of cognitive functioning which is affected in hypotension.

The relationship between blood pressure and cortical activity is also reflected in a negative correlation between blood pressure and $\alpha$ wave activity in the spontaneous EEG [47]. This suggests that low blood pressure is associated with a reduced tonic cortical arousal [53]. On the behavioral level, higher degrees of $\alpha$ activity are known to be associated with generally diminished vigilance and preparedness to react [54].

Considering the physiological processes mediating the relationship between blood pressure and brain function, it must be taken into account that blood pressure can influence cortical activation processes via afferent projections [47, 55-57]. The brain continuously receives information about the state of the cardiovascular system by means of viscero-afferent fibers [23]. These afferent signals enter the brain via brainstem nuclei. From there, ascending pathways continue via hypothalamic and thalamic regions to cortical areas such as the anterior cingulate, the insula and the prefrontal lobe [58]. The latter areas, in particular the prefrontal cortex and the anterior cingulate 
are of crucial importance in the regulation of cortical arousal, as well as for attentional processes $[59,60]$. Thus, these brain structures may represent functional interfaces between cardiovascular activity and attention [42].

Also neurochemical mediators should be regarded in the relationship between blood pressure and cortical activity. Noradrenaline is involved in the control of cortical arousal and attentional processes, as well as in the genesis of the CNV $[59,61]$. Catecholamines are also of great influence in the regulation of blood pressure [62]. Bearing this in mind, one could speculate on the neurochemical level about a specific role of noradrenaline linking cardiovascular and cortical activation.

\section{Cerebral blood perfusion in constitutional hypotension}

It is generally assumed that in healthy individuals processes of autoregulation keep the cerebral blood flow constant within a wide range of arterial pressure. In order to ensure stable perfusion, cerebral resistance vessels constrict during increases and dilate during reductions in systemic blood pressure [5]. Autoregulation is considered to be a protective mechanism which prevents brain ischemia during blood pressure decrease, and guards against capillary damage and edema formation during periods of elevated blood pressure.

Under normal conditions the limits within which cerebral blood flow is assumed to be constant are approximately between a mean arterial pressure (MAP) of 60 and $150 \mathrm{mmHg}[5,63,64]$. If blood pressure is outside of this range, cerebral blood flow rises or falls with respective increases or decreases in blood pressure. Slight reductions of blood pressure below the lower limit of autoregulation can be compensated by an increase of the extraction coefficient of oxygen from the blood. Further reductions are accompanied by symptoms such as pallor and dizziness and ultimately lead to irreversible brain damage [5].

MAP in individuals with constitutional hypotension usually does not decrease beyond the assumed lower MAP limit of autoregulation $(60 \mathrm{mmHg})$. In light of this, low blood pressure in these subjects should be compensated, and cerebral blood flow should not be affected. This assumption was challenged by Duschek and Schandry [65]. They recorded blood flow velocities by means of transcranial Doppler sonography in both middle cerebral arteries (MCA) in hypotensive individuals, defined according to the WHO [4], and in normotensive control subjects. Contrary to the current doctrine, MCA blood flow at rest was found to be substantially bilaterally reduced in hypotensives (c.f. Fig. 2).
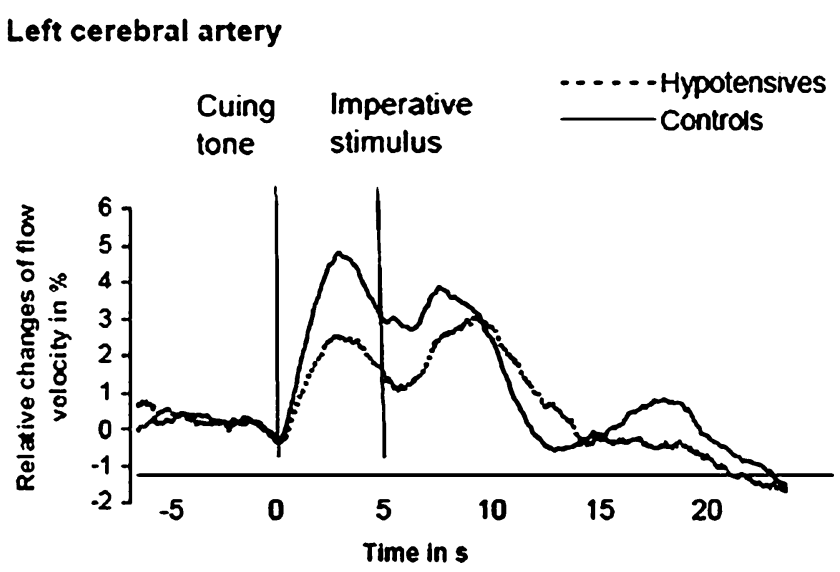

Right cerebral artery

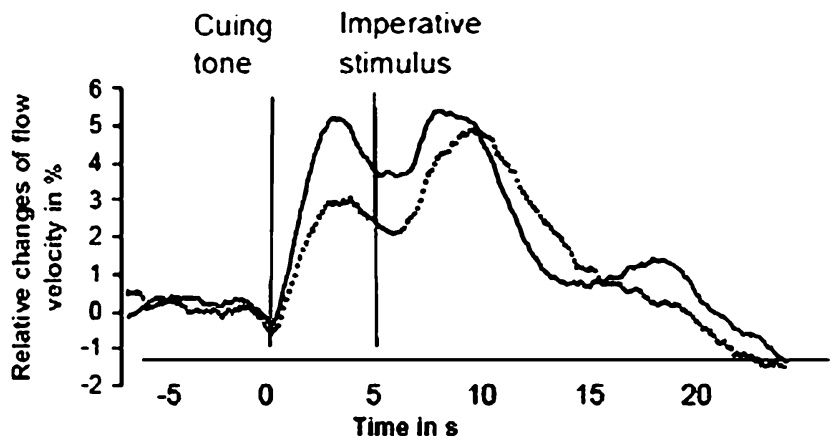

Fig. 3 Changes of blood flow velocities in the left and right MCA during the execution of an attentional task in hypotensives $(N=40)$ and controls $(N=40)$. The subjects had to press a key in response to a visual imperative stimulus which was announced by a cuing tone. In both MCA the rise in flow velocity which occurred during the anticipation of the imperative stimulus was substantially less pronounced in hypotensives. A second flow velocity maximum visible after the motor reaction was also slightly reduced in hypotensives [65]

The perfusion territory of the MCA includes subcortical areas, large fractions of the frontal and parietal lobes, as well as the temporal lobes [66]. Thus, the latter finding demonstrated that, despite autoregulation, blood pressure in subjects with constitutional hypotension is not sufficient in maintaining the perfusion of a large part of the brain at the level of normotensive individuals [see also 67].

In explaining this unexpected result, it must be noted that the determination of the lower limit of autoregulation was exclusively based on the experimental manipulation of blood pressure employing pharmacological methods, as well as head up-tilt [6871]. However, such a transient reduction of blood pressure is most certainly not comparable to conditions of chronic hypotension. Additionally, in all of these studies global cerebral blood flow was assessed by means of the oxygen difference method according to Lennox and Gibbs [72], which may be less sensitive to perfusion changes than Doppler sonography. 
Nevertheless, more recent findings suggest values for the lower MAP limit of autoregulation to be considerably higher than $60 \mathrm{mmHg}$ [73-75]. In a critical review of the literature, Drummond [76] postulated an average lower limit of no less than $70 \mathrm{mmHg}$. Moreover, the limit seems to vary strongly across individuals. Waldemar et al. [77], for instance, reported an inter-individual range between 53 and $103 \mathrm{mmHg}$. In accordance with Duschek and Schandry's [65] data, the doctrine of stable cerebral perfusion down to the limit of a MAP of $60 \mathrm{mmHg}$ can no longer be supported by the current state of research.

A further important aspect of cerebral hemodynamics concerns the continuous adjustment of brain perfusion to current requirements. Due to the close coupling of neural activity and brain metabolism, cerebral activation processes are accompanied by changes in cerebral blood flow [78]. Neurovascular coupling is based on the contraction and dilation of small resistance vessels, resulting from the changing metabolic demands of neuron populations in the vicinity [64].

With regards to hypotension-related cognitive deficits, the extent of blood flow adjustment to mental activity was also tested in the Duschek and Schandry [65] study. Subjects were presented with a simple attentional task (motor reactions to visual stimuli cued by acoustic signals). During task execution blood flow velocities in the MCA of both hemispheres were recorded by means of functional transcranial Doppler sonography (for technical details see [66]).

As expected, mental activity was accompanied by a substantial increase of MCA perfusion. In control subjects, however, this increase was approximately $70 \%$ stronger than in hypotensives (c.f. Fig. 3). It would seem that blood pressure in the latter group was not sufficient to enable adjustment of brain perfusion to cognitive demands, as seen in normotensives. Moreover, hypotensive participants showed prolonged reaction times, and a positive correlation was found between reaction speed and the extent of blood flow increase. This finding corroborates the significance of hemodynamic adjustment for optimal cognitive functioning.

\section{Final comments}

There is strong evidence suggesting that chronically low blood pressure is accompanied by diminished cognitive performance, primarily involving attention and memory $[26,29,38]$. Recent research has provided an insight into the psychophysiological mechanisms of action underlying these deficits: EEG studies have demonstrated that the weaker cognitive performance is associated with reduced cortical activity [22, 29, 47]. Furthermore, deficient regulation of cerebral blood flow must be assumed in hypotension. In addition to diminished tonic brain perfusion, reduced adjustment of brain perfusion to cognitive demands was documented [65]. It stands to reason that, as a consequence of this situation, a diminished metabolic supply of the brain tissue accounts for the cognitive deficits.

The cognitive deficits can widely affect the every day life of hypotensive persons, and more attention should therefore be allocated to this topic within basic and clinical research, as well as in clinical practice [1, 17]. This finally leads to the issue of the treatment of hypotension. Empirical knowledge concerning the effectiveness of antihypotensive therapy continues to be scant. A variety of treatment strategies such as physical training, increase of liquid intake and pharmacological measures have been suggested [1]. In two clinical trials the administration of sympathomimetics was found to result in a reduction of subjective hypotensive symptoms $[20,21]$. Recent data of our own group suggest that cognitive performance may also be enhanced by pharmacological blood pressure elevation [79]. Based on a placebo controlled design, the vasopressor agent midodrine was shown to raise cerebral blood perfusion as well as performance on a test assessing selective attention [30] in hypotensive subjects, defined according to the WHO [4]. The results of these pioneering studies are promising. Further research would appear worthwhile and should aim to establish precise guidelines which enable chronic hypotension to be efficiently and effectively dealt with in practice.

\section{References}

1. Duschek S, Schandry R (2006) Antriebsschwäche und beeinträchtigte Hirnleistungen: neue Perspektiven zum chronisch niedrigen Blutdruck. Deut Med Wochenschr 131:272-277
2. Duschek S, Schandry R (2006) Increased pain sensitivity in low blood pressure. Abstract of the 5th Congress of the Spanish Society of Psychophysiology (SEPF). Granada, Spain, September 28-30, 2006. J Psychophysiol $20: 235$
3. Pilgrim JA, Stansfeld S, Marmot M (1992) Low blood pressure, low mood? Brit Med J 304:75-78

4. WHO (1978) Arterial hypertension. Technical Report Series No. 628. World Health Organisation, Genova 
5. Chillon JM, Baumbach GL (1995) Autoregulation of cerebral blood flow. In: Welch KMA, Caplan LR, Reis DJ, Siesjö BK, Weir B (eds) Primer on cerebrovascular diseases. Academic Press, San Diego, pp 51-54

6. Tonkin A (2004) Low blood pressure and low energy: (how) are they related? J Hypertens 22:671-673

7. Wessely S, Nickson J, Cox B (1990) Symptoms of low blood pressure: a population study. Brit Med J 301:362365

8. Rosengren A, Tibblin G, Wilhelmsen L (1993) Low systolic blood pressure and self perceived wellbeing in middle aged men. Brit Med J 306:243-246

9. Barrett-Connor E, Palinkas LA (1994) Low blood pressure and depression in men: a population based study. Brit Med J 308:446-449

10. Ng PH, Walters WA (1992) The effect of chronic maternal hypotension during pregnancy. Aust NZ J Obstet Gyn 32:14-16

11. Hestad K, Kveberg B, Engedal K (2005) Low blood pressure is a better predictor of cognitive deficits than the apolipoprotein e4 allele in the oldest old. Acta Neurol Scand 111:323-328

12. Morris MC, Scherr PA, Hebert LE, Bennett DA, Wilson RS, Glynn RJ, Evans DA (2000) The cross-sectional association between blood pressure and Alzheimer's disease in a biracial community population of older persons. J Gerontol A-Biol 55:M130-M136

13. Qiu C, Winblad B, Fratiglioni L (2005) The age-dependent relation of blood pressure to cognitive function and dementia. Lancet Neurol 4:487-499

14. Zuccala G, Onder G, Pedone C, Carosella L, Pahor M, Bernabei R, Cocchi A (2001) Hypotension and cognitive impairment: selective association in patients with heart failure. Neurology 57:1986-1992

15. Heijer T, Skoog I, Oudkerk M, de Leeuw FE, de Groot JC, Hofman A, Breteler MM (2003) Association between blood pressure levels over time and brain atrophy in the elderly. Neurobiol Aging 24:307-313

16. Ruitenberg A, Skoog I, Ott A, Aevarsson O, Witteman JC, Lernfelt B, van Harskamp F, Hofman A, Breteler M (2001) Blood pressure and risk of dementia. Results from the Rotterdam study and the Gothenburg H-70 study. Dement Geriatr Cogn 12:33-39

17. Duschek S, Schandry R (2005) Subjektive Beschwerden und kognitive Minderleistungen bei essentieller Hypotonie. VT\&VM 26:5-31
18. Richter-Heinrich E, Borys M, Sprung H, Läuter J (1971) Psychophysiologische Reaktionsprofile von Hypo- und Hypertonikern. Deut Gesundheitswes 32:1481-1489

19. Cadalbert B (1997) Die Psychophysiologie des niedrigen Blutdrucks: Kreislaufregulation, Lebensgewohnheiten und Beschwerden. Peter Lang, Frankfurt a.M

20. Bismarck M, Rust G (1982) Erste Erfahrungen mit dem Antihypotonikum Thomasin (=Etilefrin) unter ambulanten Bedingungen (eine Doppelblindstudie). Z Ärztliche Fortb 76:153-156

21. Schandry R (1999) Die Verbesserung der subjektiven Befindlichkeit bei orthostatischer Hypotonie unter dem Einfluss blutdrucksteigernder Therapie. Med Welt 50:160-165

22. Weisz N, Schandry R, Jacobs A, Mialet J, Duschek S (2002) Early contingent negative variation of the EEG and attentional flexibility are reduced in hypotension. Int J Psychophysiol 45:253-260

23. Dembowsky K, Seller H (1995) Arterial baroreceptor reflexes. In: Vaitl D, Schandry R (eds) From the heart to the brain: the psychophysiology of circulation-brain interaction. Europäischer Verlag der Wissenschaften, Frankfurt a.M., pp 35-60

24. Igler FO, Donegan JH, Hoo KC, Korns ME, Kampine JP (1981) Chronic localized hypotension and resetting of carotid sinus baroreceptors. Electrophysiological and histological studies in the dog. Circ Res 49:649-654

25. Abels D (1954) K-V-T. KonzentrationsVerlaufs-Test. Hogrefe, Göttingen

26. Stegagno L, Angrilli A, Costa M, Palomba D (1996) Deficit cognitivi e ipotensione arteriosa: Un indagine cronopsycofisiologica. G Ital Psicol 23:837-859

27. Wechsler D (1962) Wechsler memory scale. Forma I. Adattazione Italaliana di E. Cimino. Organizzazioni Speciali, Firence

28. Baddeley A (1982) Your memory. A user's guide. Multimedia Publications, London

29. Costa M, Stegagno L, Schandry R, Bitti PER (1998) Contingent negative variation and cognitive performance in hypotension. Psychophysiology 35:737-744

30. Brickenkamp R (1994) Test d2, Aufmerksamkeits-Belastungs-Test. Hogrefe, Göttingen

31. Oswald WD, Roth E (1987) Der ZahlenVerbindungs-Test (ZVT) - Ein sprachfreier Intelligenz-Test zur Messung der "kognitiven Leistungsgeschwindigkeit". Hogrefe, Göttingen
32. Morris MC, Scherr PA, Hebert LE, Bennett DA, Wilson RS, Glynn RJ, Evans DA (2002) Association between blood pressure and cognitive function in a biracial community population of older persons. Neuroepidemiology 21:123-130

33. Albert M (1993) Neuropsychological changes in healthy adult humans across the age range. Neurobiol Aging 14:623625

34. Smith A (1984) Symbol digit modalities test. Manual - Revised. Western Psychological, Los Angeles

35. Folstein MF, Folstein SE, McHugh PR (1975) Mini mental state. A practical method for grading the cognitive state of patients for the clinician. J Psychiat Res 12:189-198

36. Mialet JP, Jacobs A, Bisserbe JC (1995) Computerized attentional and cognitive efficiency battery: preliminary results. Eur J Psychol Assess 11(suppl. 1):111

37. Duschek S, Weisz N, Schandry R (2003) Reduced cognitive performance and prolonged reaction time accompany moderate hypotension. Clin Auton Res 13:427-432

38. Duschek S, Matthias E, Schandry R (2005) Essential hypotension is accompanied by deficits in attention and working memory. Behav Med 30:149-158

39. Zimmermann P, Fimm B (2002) Testbatterie zur Aufmerksamkeitsprüfung (TAP). Version 1.7. Handbuch Teile 1 und 2. Psytest, Herzogenrath

40. Schoppe KJ (1974) Das MLS-Gerät. Ein neuer Testapparat zur Messung feinmotorischer Leistungen. Diagnostica 20:43-46

41. Von Zerssen D (1976) Klinische Selbstbeurteilungs-Skalen aus dem Münchner Psychiatrischen Informations-System (PSYCHIS) München. Die Befindlichkeitsskala, Beltz, Weinheim

42. Critchley HD, Mathias CJ (2003) Blood pressure, attention and cognition: drivers and air traffic controllers. Clin Auton Res 13:399-401

43. Shapiro D, Miller RE, King HE, Ginchereau EH, Fitzgibbon K (1982) Behavioral consequences of mild hypertension. Hypertension 4:355-360

44. Waldstein SR, Ryan CM, Manuck SB, Parkinson DK, Bromet EJ (1991) Learning and memory function in men with untreated blood pressure elevation. J Consult Clin Psychol 59:513-517

45. Pandav R, Dodge HH, DeKosky ST, Ganguli M (2003) Blood pressure and cognitive impairment in India and the United States: a cross-national epidemiological study. Arch Neurol 60:11231128 
46. Waldstein SR, Giggey PP, Thayer JF, Zonderman AB (2005) Nonlinear relations of blood pressure to cognitive function: the Baltimore Longitudinal Study of Aging. Hypertension 45:374379

47. Duschek S, Meinhardt J, Schandry R (2006) Reduced cortical activity due to chronic low blood pressure: an EEG study. Biol Psychol 72:241-250

48. Tecce JJ, Cattanach L (1993) Contingent negative variation. In: Niedermeyer E, Lopes da Silva F (ed) Electroencephalography: basic principles clinical applications, and related fields. Urban \& Schwarzenberg, Baltimore, pp 657-679

49. Coons HW, Peloquin LJ, Klorman R, Bauer LO, Ryan RM, Perlmutter RA, Salzman LF (1981) Effect of methylphenidate on young adult's vigilance and event-related potentials. Electroen Clin Neuro 51:373-387

50. Fattaposta F, Floris R, Sanarelli L, Terribile P, Tilia G (1984) Changes in slow cerebral potentials (CNV) subsequent to midazolam administration. Double-blind study. Riv Neurol 54:289298

51. Chao LL, Meyerhoff DJ, Cardenas VA, Rothlind JC, Weiner MW (2003) Abnormal CNV in chronic heavy drinkers. Clin Neurophysiol 114:20812095

52. Claverie B, Brun A, Nizard A, Brenot $P$, Paty J (1984) Multiparametric outlines with CNV: applications to depressive syndromes. In: Karrer R, Cohen J, Tueting $\mathrm{P}$ (eds) Brain and information: event-related potentials. New York Academy of Sciences, New York, pp 556-564

53. Andreassi JL (2000) Human behavior and physiological response. Lawrence Erlbaum, London

54. Davidson RJ, Jackson DC, Larson CL (2000) Human electroencephalography. In: Cacioppo JT, Tassinary LG, Berntson GG (eds) Handbook of psychophysiology. Cambridge University Press, New York, pp 27-52

55. Goldstein MA, Silverman ME (2006) Autonomics and cognition. Clin Auton Res 16:86-89
56. Heims HC, Critchley HD, Martin NH, Jäger HR, Mathias CJ, Cipolotti L (2006) Cognitive functioning in orthostatic hypotension due to pure autonomic failure. Clin Auton Res 16:113120

57. Vaitl D, Gruppe H (1991) Baroreceptor stimulation and changes in EEG and vigilance. In: Perssons PB, Kirchheim HR (eds) Baroreceptor reflexes: integrative functions and clinical aspects. Springer, Berlin, pp 293-313

58. Craig AD (2003) Interoception: the sense of the physiological condition of the body. Curr Opin Neurobiol 13:500505

59. Gómez CM, Vaquero E, VázquezMarrufo M (2004) A neurocognitive model of short-term sensory and motor preparatory activity in humans. Psicológica 25:217-229

60. Sturm W, de Simone A, Krause BJ, Specht K, Hesselmann V, Radermacher I, Herzog H, Tellmann L, Muller-Gartner HW, Willmes K (1999) Functional anatomy of intrinsic alertness: evidence for a fronto-parietal-thalamic-brainstem network in the right hemisphere. Neuropsychologia 37:797-805

61. Posner MI, Petersen SE (1990) The attention system of the human brain. Annu Rev Neurosci 13:25-42

62. Carlson NR (2004) Physiology of behavior. Pearson Education, Harlow

63. Jennings JR (2003) Autoregulation of blood pressure and thought: preliminary results of an application of brain imaging to psychosomatic medicine. Psychosom Med 65:384-395

64. Paulson OB (2002) Blood-brain barrier, brain metabolism and cerebral blood flow. Eur Neuropsychopharm 12:495-501

65. Duschek S, Schandry R (2004) Cognitive performance and cerebral blood flow in essential hypotension. Psychophysiology 41:905-913

66. Duschek S, Schandry R (2003) Functional transcranial Doppler sonography as a tool in psychophysiological research. Psychophysiology 40:436-454

67. Duschek S, Schandry R (2006) Deficient adjustment of cerebral blood flow to cognitive activity due to chronically low blood pressure. Biol Psychol 72:311-317
68. McHenry LC, West JW, Cooper ES, Goldberg HI, Jaffe ME (1974) Cerebral autoregulation in man. Stroke 5:695706

69. Olesen J (1973) Quantitative evaluation of normal and pathologic cerebral blood flow regulation to perfusion pressure. Changes in man. Arch Neurol (Chicago) 28:143-148

70. Strandgaard S (1976) Autoregulation of cerebral blood flow in hypertensive patients. The modifying influence of prolonged antihypertensive treatment on the tolerance to acute, drug-induced hypotension. Circulation 53:720-727

71. Strandgaard S, Olesen J, Skinhoj E, Lassen NA (1973) Autoregulation of brain circulation in severe arterial hypertension. Brit Med J 1:507-510

72. Lennox WG, Gibbs EL (1932) The blood flow in the brain and the leg of man and the changes induced by alternation of blood gases. J Clin Invest 11:1155-1177

73. Larsen FS, Olsen KS, Hansen BA, Paulson OB, Knudsen GM (1994) Transcranial Doppler is valid for determination of the lower limit of cerebral blood flow autoregulation. Stroke 25:1985-1988

74. Olsen KS, Svenden LB, Larsen FS, Paulson OB (1995) Effect of labetalol on cerebral blood flow, oxygen metabolism and autoregulation in healthy humans. Br J Anaesth 75:51-54

75. Olsen KS, Svendsen LB, Larsen FS (1996) Validation of transcranial nearinfrared spectroscopy for evaluation of cerebral blood flow autoregulation. J Neurosurg Anaesth 8:280-285

76. Drummond JC (1997) The lower limit of autoregulation: time to revise our thinking? Anesthesiology 86:1431-143

77. Waldemar G, Schmidt JF, Andersen AR, Vorstrup S, Ibsen H, Paulson OB (1989) Angiotensin converting enzyme inhibition and cerebral blood flow autoregulation in normotensive and hypertensive man. J Hypertens 7:229235

78. Kuschinsky W (1991) Coupling of function, metabolism, and blood flow in the brain. Neurosurg Rev 14:163-168

79. Duschek S, Hadjamu M, Schandry R (2006) Enhancement of cerebral blood flow and cognitive performance due to pharmacological blood pressure elevation in chronic hypotension. Psychophysiology 44:(in press) 